\title{
PENINGKATAN PENGETAHUAN SISWA TENTANG MATERI MANFAAT SIG TERHADAP MITIGASI BENCANA MELALUI PEMANFATAAN MEDIA BERBASIS SIG DI SMAN 5 PADANG TAHUN PELAJARAN 2018/2019
}

\author{
Rahmat Hidayat ${ }^{1}$, Yurni Suasti ${ }^{2}$ \\ Program Studi Pendidikan Geografi, \\ Fakultas Ilmu Sosial, Universitas Negeri Padang \\ Email rahmathidayat2323@ymail.com
}

\begin{abstract}
ABSTRAK
Penelitian ini bertujuan untuk mengetahui peningkatan pengetahuan siswa sebelum dan sesudah menggunakan media berbasis SIG di SMAN 5 Padang.Jenis penelitian adalah penelitian Eksperimen Quasi dengan subyek penelitian siswa kelas XII IPS 1 di SMAN 5 Padang. Teknis analisis data yang digunakan Paired Sampel T-Test. Penelitian ini menemukan peningkatan hasil belajar siswa yang signifikat tentang materi Manfaat SIG Terhadap Mitigasi Bencana setelah dilakukannya perlakuan belajar dengan menggunakan media berbasis SIG dibandingkan sebelum dilakukan perlakuan menggunakan media berbasis SIG.
\end{abstract}

Kata Kunci: Hasil Belajar, Media Pembelajaran, Pengetahuan, Sistem Informasi Geografi

\section{ABSTRACT}

This research aims to know increasing of student's knowledge before and after using GIS based media in SMA Negeri 5 Padang. This type of research is an experimental study with the student's of XII IPS1 in SMA Negri 5 Padang as the subject. The data analysis techniques used a Paired T-Test Approach. The results of this research found that the student learning outcome was increased after learning using GIS based media compared to before GIS based media.

Keyword: Learning Outcomes, Learning Media, Knowledge, Geographic Information Systems

\footnotetext{
${ }^{1}$ Mahasiswa Program Studi Pendidikan Geografi Untuk Wisuda September 2018

${ }^{2}$ Dosen Jurusan Geografi Fakultas Ilmu Sosial Unversitas Negeri Padang dengan Pembimbing Dra Yurni Suasti, M.Si
} 


\section{PENDAHULUAN}

Materi geografi memiliki pembahasan yang sangat beragam, salah satu materi geografi yaitu tentang manfaat SIG terhadap mitigasi bencana yang di ajarkan di kelas XII IPS .SIG merupakan suatu sistem yang digunakan untuk

mengumpulkan, mengelola, menganalisis, dan menyajikan data spasial menggunakan teknologi (Aronoff; 1989)

Materi manfaat SIG terhadap mitigasi bencana merupakan materi yang banyak menggunakan praktik berbasis informasi teknologi (IT) sehingga penyampaian materi ini kesiswa harus dengan caramedia berbasis IT yang dilakukan secara praktik, agar siswa bisa ikut terlibat dalam pembelajaran. Menurut Suasti (2003) dalam pembelajaran, siswa harus memiliki tanggung jawab yang lebih besar dan aktif dibandingkan guru dalam melaksanakan pembelajaran.

Penggunaan media untuk kegiatan pembelajaran sangat penting dalam meningkatkan minat belajar siswa.Menurut Bovee (1997) media adalah berbagai jenis komponen dalam lingkungan siswa yang dapat merangsang untuk belajar.Menurut Gagne (1970) media adalah berbagai jenis komponen dalam lingkungan siswa yang dapat merangsang untuk belajar.

Pemanfaatan IT juga bisa digunakan sebagai media pembelajaran yang inovatif. Penerapan media Pembelajaran berbasis IT di bidang pendidikan, diyakini dapat Memberikan perubahan yang signifikat dalam meningkatkan hasil belajar siswa. Berdasarkan hal tersebut peneliti sangat tertarik untuk mengkaji lebih jauh dan mendalam mengenai pengaruh penggunaan media pembelajaran berbasis IT dalam proses pembelajaran terhadap peningkatan hasil belajar siswa.

Menurut Nugroho (2005), ada beberapa permasalahan yang dihadapi sekolah menengah di Indonesia dalam memanfaatkan IT sebagai media pembelajaran antara lain, (a) media pembelajaran berbasis IT membutuhkan danayang cukup besar baik untuk pengadaan maupunpemeliharaannya, (b) belum mendukungnya fasilitas/sarana-prasarana/infrastruktur seperti listrik, (c)masih kurangnya guru dan sumber daya pengajar yang berkompeten dalam memanfaatkan TI sebagai media pembelajaran dan (d) sumber informasi dan referensi yang masih sangat kurang.

Hasil pengamatan yang dilakukan di sekolah SMAN 5 Padang di kelas XII IPS 1, guru masih menyampaikan pembelajaran dengan metode ceramah tentang materi manfaat SIG terhadap mitigasi bencana, sehingga hal itu berdampak pada kurangnya minat belajar siswa terhadap materi dan rendahnya hasil belajar siswa.

Berdasarkan penjelasan di atas maka tujuan dari penelitian ini untuk membandingkan pengetahuan siswa kelas XII IPS 1 tentang materi manfaat SIG terhadap mitigasi bencana sebelum dan sesudah pemanfaatan media berbasis sistem informasi geografi di SMAN 5 Padang tahun pelajaran 2018/2019.

\section{METODE PENELITIAN}

Jenis penelitian ini adalah penelitian eksperimen quasi dengan cara one group pretest-posttest. Menurut Sukardi (2010) pretest diberikan untuk melihat kondisi awal hasil belajar siswa dan posttest untuk melihat ada tidaknya peningkatan hasil belajar siswa setelah dilakukan perlakuan.

Teknik analisis paired sampel t-test dengan menggunakan aplikasi SPSS.Penelitian ini dilakukan di SMA Negeri 5 Padang kelas XII IPS. 
1, peta lokasi penelitian dapat dilihat pada gambar 1 .

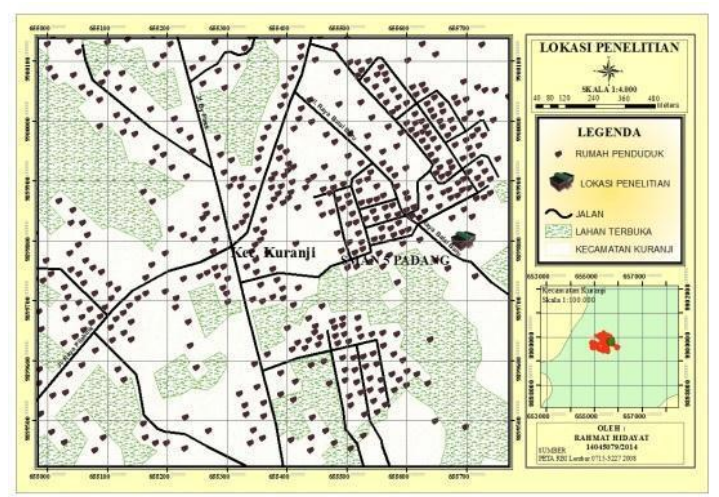

Gambar 1. Lokasi Penelitian

\section{HASIL DAN PEMBAHASAN}

Sebelum dilakukan perlakuan, dilakukan terlebih dahulu prestest selama 60 menit terhadap kelas sampel untul mengetahui kondisi awal siswa dan setelah dilakukan perlakukan diadakan posttest untuk menguji peningkatan pengetahuan siswa setelah diberikan perlakukan.Data hasil pretest dan posttest dapat dilihat pada tabel 1.

Tabel 1. Rata-rata Hasil Belajar Pre Test dan Post Test Eksperiment

\begin{tabular}{lllll}
\hline No & Test & Nilai Min & Nilai Maks & Rata-rata \\
\hline 1 & Pretest & 26,66 & 70 & 53,19 \\
\hline 2 & Posttest & 60 & 83,33 & 74,86 \\
\multicolumn{4}{l}{ Sumber : Olahan data primer (2018) }
\end{tabular}

Sumber : olahan data primer (2018)

Uji normalitas dilakukan pada kelas sampel dan didapat harga dan pada taraf nyata 0,05 seperti pada tabel 2 .

Tabel 2. Hasil Uji Normalitas Data Hasil Belajar Siswa

Tabel 2 Hasil Uji Normalitas Data Hasil Belajar Siswa

\begin{tabular}{cccc}
\hline Test & N & & \\
\hline Pretest & 24 & 0,1209 & 0,181 \\
\hline Posttest & 24 & 01743, & 0,181
\end{tabular}

Sumber : olahan data primer Excel (2018)

Dari tabel 2 diketahui bahwa dengan demikian dapat disimpulkan harga ( ) untuk kedua Test bahwa data hasil belajar kedua test kurang dari atau , berdistribusi normal. 
Analisis paired sampel t-test digunakan untuk melihat ada atau tidak adanya perbedaan hasil belajar prestest dan posttest secara signifikat. Berikuthasil analisis paired sampel t-test bisa dilihat pada tabel 3.

Tabel 3 Tabel Paired Sampel T-Test Pre Test dan Post Test

\begin{tabular}{|c|c|c|c|c|c|c|c|}
\hline & \multicolumn{4}{|c|}{ Paired Differences } & \multirow[b]{3}{*}{$\mathrm{T}$} & \multirow[b]{3}{*}{ Df } & \multirow{3}{*}{$\begin{array}{l}\text { Sig. } \\
(2- \\
\text { taile } \\
\text { d) }\end{array}$} \\
\hline & \multirow[b]{2}{*}{ Mean } & \multirow{2}{*}{$\begin{array}{r}\text { Std. } \\
\text { Deviatio } \\
\mathrm{n}\end{array}$} & \multirow{2}{*}{$\begin{array}{l}\text { Std. } \\
\text { Error } \\
\text { Mean }\end{array}$} & $\begin{array}{c}95 \% \text { Confidence } \\
\text { Interval of the } \\
\text { Difference }\end{array}$ & & & \\
\hline & & & & Lower Upper & & & \\
\hline$\overline{\text { Pair PRETEST - }}$ & & & & - & - & & \\
\hline 1POSTTEST & & & 63087 & $58925,7334317,59$ & $\begin{array}{r}11,02 \\
1\end{array}$ & & 23,000 \\
\hline
\end{tabular}

Sumber : olahan data primer SPSS (2018)

Diketahui bahwa nilai signifikan (2tailed) sebesar $0,000<0,05$, maka kita dapat simpulkan bahwa terdapat perbedaan yang signifikan antar hasil belajar pada data pretest dan posttest.

$\mathrm{H}$

as

il analisis data

bahwa nilai rata-rata pada hasil belajar pretest dan posttest adalah 53,1944 dan 74,8611, hal ini menunjukan bahwa rata-rata hasil belajar posttest lebih baik dari hasil belajar pretest. Dilihat dari segi ketunta

san belajar secara individu, diperoleh pada hasil belajar posttest nilai siswa yang diatas atau sama dengan KKM yang diterapkan sekolah 70 adalah 19 orang siswa atau 63,333\% sedangkan hasil belajar Pre Test sebanyak 1 orang siswa atau 3,333\%. Jadi dapat disimpulkan bahwa hasil belajar pada posttest setelah dilakukan perlakuan memperoleh nilai diatas atau sama dengan KKM lebih banyak dari pada

terlihat sebelum dilakukannya

perlakuan menggunakan media berbasis SIG.

Selama kegiatan pembelajaran menggunakan media berbasis SIG ini, siswa kelas XII IPS 1 lebih

semangat dalam belajar dan lebih termotivasi untuk berpatispasi dalam diskusi.Dengan adanya media berbasis SIG ini, siswa lebih mudah dalam memahami materi mengenai manfaat SIG terhadap mitigasi bencana, karena siswa memperhatikan secara langsung bagaimana SIG membantu dalam mitigasi bencana.

Setelah diadakannya perlakuan menggunakan media berbasis SIG, dari 5 Indikator, Indikator 4 mengenai Manfaat SIG dalam membantu penilaian kerusakan (Damage Assesment) mempunyai tingkat pemahaman yang lebih rendah dari Indikator lain yaitu sebesar 55,83\%. Sementara tingkat pemahaman yang lebih tinggi 
terdapat pada indikator 5 tentang manfaat SIG dalam membantu tingkat rawat banjir sebesar $75 \%$,dan disusul oleh Indikator 1 dan 3

tentang manfaat SIG dalam memantau luas wilayah terdampak bencana dan manfaat SIG dalam

menyusun

rencana-rencana

pembangunan kembali daerah bencana sebesar 63,33 \% dan Indikator 2 tentang manfaat SIG

dalam pencegahan terjadinya bencana alam pada masa yang akan datang sebesar $62,5 \%$. Solusi yang yang bisa saya berikan kepada indikator 4 yang memiliki tingkat pemahaman yang lebih rendah yaitu dengan cara menambahkan contoh studi kasus media berbasis SIG yang lain agar siswa lebih banyak

mendapatkan sumber sehingga meningkatkan kemampuan daya

pemahaman siswa.Berdasarkan kajian teori, bahwasanya media

berbasis SIG ini mampu meningkatkan motivasi siswa dalam minat belajar, sehingga berpengaruh terhadap hasil belajar siswa itu sendiri.

Berbeda halnya dengan pembelajaran yang hanya bersifat ceramah tanpa menggunakan media berbasis SIG sendiri. Pemikiran siswa akan ngambang karena tidak adanya praktik yang dilakukan oleh guru dalam menjelaskan materi tersebut. Sehingga motivasi siswa dalam belajar menjadi berkurang dan berdampak pada hasil belajar siswa itu sendiri.
Penelitian sejenis yang dilakukan oleh Utama (2013) tentang materi kompetensi dasar pemanfaatan sistem informasi geografi yang di lakukan di SMA Negeri 1 Grobongan tahun pelajaran 2014/2015 menemukan bahwa pembelajaran yang menggunakan media berbasis SIGdapat meningkatkan hasil belajar siswa. Sebelum penggunaan media berbasis SIG nilai rata-rata aspek kognitif pretest 60.67 sedangkan pada ratarata nilai post test setelah dilakukan perlakuan yaitu 76.08, terdapat kenaikan yang signifikat sebelum dan sesudah penggunaan media berbasis SIG sebesar 15,41\%.

\section{PENUTUP}

\section{Kesimpulan}

Berdarkan hasil penelitian yang peneliti lakukan, maka dapat diambil kesimpulan bahwa:

Hasil belajar geografi siswa kelas XII IPS 1 SMA Negeri 5 Padang tentang materi manfaat SIG terhadap mitigasi bencana mengalami kenaikan yang signifikat dibandingkan sebelum dilakuannya perlakuan menggunakan media berbasis sistem informasi geografi

(SIG). Karena pembelajaran menggunakan media berbasis SIG ini, dapat meningkatkan motivasi siswa dalam minat belajar sehingga berdampak pada mudahnya siswa dalam memahami materi yang disampaikan oleh guru. 
Saran

Sehubungan dengan hasil penelitian yang telah diperoleh maka peneliti memberikan saran sebagai berikut:

1. Disarankan bagi guru untuk menerapkan media berbasis sistem informasi geografi dalam proses pembelajaran mengajar sehingga membuat siswa lebih bisa berperan aktif pada saat bekerjasama.

2. Penelitian yang dilakukan oleh peneliti masih terbatas pada pemahaman mata pelajaran geografi tentang pemanfaatan SIG terhadap mitigasi bencana, oleh karena itu diharapkan kepada rekan-rekan peneliti selanjutnya untuk dapat melanjutkan penelitian dengan pokok bahasan lain.

\section{DAFTARPUSTAKA}

Agung Nugroho, 2005. Strategi Jitu Memilih Metode Statistic Penelitian DenganSPSS, Andi Yogyakarta, Yogyakarta.

Aronoff,Stan.

1989.GeographicInformation

System and

ManagementPerspective.
WDLPublication, OttawaCanad.

Bovee.Courland.(1997). Business

Communication Today.

Prentice Hall : New York

Gagne, Robert $M$ and Leslie $J$ Briggs.1970.Principles of

Instructional Design.Harcourt

Brace Jovanivich College

Publisher.San Diego

Suasti Yurni. 2003. Upaya

Peningkatan Kreativitas

Siswa SMU Pembangunan

UNP Melalui Modifikasi

Cooperative Learning Model

Jigsaw.Universitas Negeri

Padang.Jurnal.

Sukardi. 2010. Metode Penelitian Pendidikan. Jakarta: Bumi Aksara.

Utama Tommy Mandika, 2013. Pemanfaatan Media

Pembelajaran Berbasis

Sistem Informasi Geografi

Pada Mata Pelajaran

Geografi Kompetensi Dasar

Pemanfataan Sistem

Informasi Geografi Kelas XII

SMA Negeri 1 GROBOGAN

Tahun Pelajaran 2014/2015.

Skripsi 